\title{
Eficiência de fungicidas no controle da brusone em trigo
}

\author{
João Romero do Amaral Santos de Carvalho Rocha ${ }^{1}$, Adérico Júnior Badaró Pimentel ${ }^{1}$, Guilherme Ribeiro ${ }^{2}$, Moacil \\ Alves de Souza ${ }^{1}$
}

${ }^{1}$ Universidade Federal de Viçosa, Campus Viçosa, Avenida Peter Henry Rolfs, s/n, CEP 36570-900, Viçosa, MG. ${ }^{2}$ Universidade Federal do Pampa, Campus Itaqui, Rua Luiz Joaquim de Sá Britto, s/n, CEP 97650-000, Itaqui, RS.

Autor para correspondência: João Romero do Amaral Santos de Carvalho Rocha (joaoascrocha@gmail.com)

Data de chegada: 09/10/2013. Aceito para publicação em: 03/11/2014.

$10.1590 / 0100-5405 / 1937$

\section{RESUMO}

Rocha, J.R.A.S.C.; Pimentel, A.J.B.; Ribeiro,G.; Souza, M.A.. Eficiência de fungicidas no controle da brusone em trigo. Summa Phytopathologica, v.40, n.4, p.347-352, 2014.

Causada pelo fungo Pyricularia grisea, a brusone do trigo constitui-se num dos principais entraves à expansão da produção tritícola no Brasil Central. O objetivo deste trabalho foi avaliar a eficiência de fungicidas no controle da brusone em trigo. Foram utilizados três fungicidas, com princípios ativos distintos, combinados com quatro genótipos de trigo. Realizaram-se duas aplicações do produto comercial, sendo estas no estádio 45 e 65 da escala de Zadokset al. A inoculação artificial com os esporos de $P$. grisea ocorreu no estádio 58-60 da referida escala. Determinou-se a área abaixo da curva de progresso da doença (AACPD), a severidade em folhas bandeira (SEVFB) e em espigas (SEVEsp) e quantificou-se a produção de grãos (PG).Ao final do trabalho, os diferentes parâmetros analisados foram submetidos à análise de correlação de Pearson.Os fungicidas epoxiconazol+piraclostrobina e tebuconazol+trifloxistrobina foram os que proporcionaram menor AACPD nos genótipos VI 03061, VI 07505 e BRS 254. Não houve diferença para SEVFB entre os genótipos na presença de fungicidas. As linhagens VI 98053 e VI 07505 apresentam menor SEVFB na ausência de fungicidas.O fungicida tebuconazole+trifloxistrobina proporcionou maior PG e menor SEVEsp. A severidade da doença em espigas foi maior do que em folhas bandeira. O controle da brusoneem trigo através da aplicação de fungicidas mostrou-se eficiente em folhas bandeira, mas não eficiente para o controle nas espigas.

Palavras-chave adicionais: Triticum aestivum, Pyricularia grisea, controle químico.

\section{ABSTRACT}

Rocha, J.R.A.S.C.; Pimentel, A.J.B.; Ribeiro,G.; Souza, M.A. Efficiency of fungicides in wheat blast control. Summa Phytopathologica, v.40, n.4, p.347-352, 2014.

Wheat blast, caused by the fungus Pyricularia grisea, constitutes one of the major obstacles to the expansion of wheat production in Central Brazil. The aim of this study was to evaluate the efficiency of fungicides in the control of wheat blast. Three fungicides with different active ingredients and combined with four wheat genotypes were used. Two applications of the commercial product were performed in stages 45 and 65 of the scale of Zadoks et al. Artificial inoculation with P. grisea spores was done in stages 58-60 of the above-mentioned scale. The area under the disease progress curve (AUDPC), the severity on flag leaves (SEVFL) and the severity on spikes (SEVEsp) were determined, and grain yield (GY) was quantified. At the end of the experiment, different analyzed parameters were subjected to Pearson's correlation analysis. The fungicides epoxiconazole+pyraclostrobin and tebuconazole+trifloxystrobin provided the lowest AUDPC for the genotypes VI 03061, VI 07505 and BRS 254. There was no difference for SEVFL among genotypes in the presence of fungicides. The genotypes VI 98053 and VI 07505 showed the lowest SEVFL in the absence of fungicide. Tebuconazole+trifloxystrobin provided higher GY and lower SEVEsp. The disease severity on the ears was greater than on flag leaves. Control of wheat blast by means of fungicide application was effective for flag leaves but not for ears.

Additional keywords: Triticum aestivum, Pyricularia grisea, chemical control.

A cultura do trigo no centro-oeste brasileiro é conduzida em sistema irrigado ou em sequeiro. O cultivo irrigado, realizado principalmente sob pivô central, fornece condições adequadas à manutenção de ambiente favorável ao desenvolvimento de algumas doenças fúngicas. Por outro lado, o cultivo de sequeiro, com semeadura realizada entre os meses de fevereiro e março, associa temperatura elevada e ocorrência de chuvas durante a fase de espigamento da cultura, o que potencializa a incidência de doenças fúngicas como a brusone.

Causada pelo fungo Pyricularia grisea (Cooke) Saccardo = Pyricularia oryzae Cavara [teleomorfo Magnaporthe grisea (Hebert)
Barr], essa doença constitui um dos principais entraves à expansão da produção tritícola no Brasil Central (19). Danos de produtividade da ordem de até $74 \%$ são citadas por Goulart et al. (18) em lavouras no Mato Grosso do Sul. Além de danos quantitativos, a qualidade dos grãos também pode ser afetada em virtude da formação de grãos deformados, de tamanho reduzido e com baixo peso específico (18).

O uso de cultivares resistentes é o melhor método de controle de doenças, tanto pelas vantagens do ponto de vista econômico, quanto ambiental. Nesse contexto, o desenvolvimento de cultivares resistente é prioridade nos programas de melhoramento de trigo destinados a 
gerar cultivares para o cultivo em locais com histórico de ocorrência de brusone no Brasil (10). Contudo, representa um desafio para os melhoristas devido à ampla variabilidade genética do patógeno (25) e ao reduzido número de fontes de resistência encontradas em trigo comum (10).

No caso da brusone, o desenvolvimento de cultivares resistentes torna-se mais necessário em virtude da baixa eficiência dos fungicidas recomendados para a cultura $(16,23)$. Essa baixa eficácia do controle químico é decorrente da diversidade de isolados existentes, com diferentes padrões de virulência (25), associada a distintas condições de ambiente e grau de suscetibilidade das cultivares (9).

Entretanto, haja vista a disponibilidade limitada de cultivares resistente à brusone e adaptadas às distintas condições de cultivo de trigo no Brasil, o controle químico ainda é a principal alternativa utilizada no manejo da cultura por parte dos produtores (6).

Desse modo, apesar da baixa eficiência do controle químico relatado na literatura, a comparação da eficiência de fungicidas com princípios ativos distintos, bem como o estudo da sua interação com diferentes genótipos é de primordial importância para recomendação aos produtores.

Pesquisas com objetivos semelhantes têm sido conduzidas em culturas como arroz $(12,15,21)$, soja $(20,14)$, feijão $(13,27)$ e outras. No entanto, para a cultura do trigo os trabalhos disponíveis sobre controle químico da brusone são limitados.

Neste contexto, este trabalho foi desenvolvido com o objetivo de avaliar a eficiência de três fungicidas com princípios ativos distintos no controle da brusone em trigo.

\section{MATERIAL E MÉTODOS}

O trabalho foi conduzido em ambiente protegido no campo experimental da Universidade Federal de Viçosa, em Viçosa-MG (2045'14'S, 42 52'55'W, a $648 \mathrm{~m}$ de altitude).

Foram utilizados três fungicidas, com princípios ativos distintos, combinados com quatro genótipos. Os tratamentos foram dispostos em delineamento inteiramente ao acaso em esquema fatorial $4 \times 4$ : quatro genótipos e três fungicidas e uma testemunha de cada cultivar sem aplicação, com cinco repetições para cada tratamento. A unidade experimental foi composta por um vaso de oito litros contendo cinco plantas.

Os genótipos utilizados foram a cultivar BRS 254, recomendada para cultivo irrigado no Brasil Central (6), e as linhagens elites VI 03061, VI 98053 e VI 07505, desenvolvidas pelo programa de melhoramento genético de trigo da Universidade Federal de Viçosa.

Quanto aos fungicidas, foram avaliados os ingredientes ativos epoxiconazol+piraclostrobina, tebuconazol e tebuconazol+trifloxistrobina na dose de $0,5,0,75$ e 0,75 L.ha $^{-1}$ do produto comercial, respectivamente, conforme recomendado para a cultura (3). Além destes produtos, foi considerado o tratamento sem aplicação como testemunha.

A aplicação dos fungicidas foi realizada em duas épocas, seguindo a recomendação técnica para a cultura do trigo (3). A primeira aplicação, de forma preventiva, foi realizada na fase final do emborrachamento, no estádio 45 da escala de Zadoks et al. (28). Quando as plantas atingiram o estádio 58-60 da referida escala, foram inoculadas artificialmente com esporos de $P$. grisea.

O isolado utilizado foi o Pg 008, proveniente de São Gotardo (MG), que apresenta elevado espectro de virulência (22). O inóculo foi obtido conforme metodologia utilizada por Urashima et al. (25). Inicialmente o isolado foi repicado em placas de Petri contendo meio de cultura BDA (batata, dextrose e água) e mantido sob condições de regime de luz de 12 horas e temperatura de $25^{\circ} \mathrm{C}$. Quando formadas as colônias, as mesmas foram transferidas para outras placas até a obtenção de uma colônia pura. Foram então repicadas em meio de aveia ( $60 \mathrm{~g}$ de farinha de aveia, 12 g de ágar em $1 \mathrm{~L}$ de água) para a esporulação do fungo. As placas foram mantidas à temperatura de aproximadamente $25^{\circ} \mathrm{C} \mathrm{e}$ regime de luz de 12 horas durante 10 dias. Após esse período, o micélio aéreo foi retirado com bastão de vidro e água destilada-esterilizada e colocados em câmara sob luz fluorescente constante à temperatura de $25^{\circ} \mathrm{C}$, durante quatro dias para esporular. Os esporos foram removidos com água destilada e filtrados em lenço de papel. A suspensão obtida foi calibrada em hematocitômetro, em microscópio óptico, obtendo-se a concentração de $1,2 \times 10^{5}$ esporos $\mathrm{mL}^{-1}$, a qual foi pulverizada em cada uma das plantas até o total molhamento da superfície.

Após a inoculação, a presença de água livre sobre folhas e espigas foi mantida por 12 horas. A temperatura do ar permaneceu na faixa de 12 a $33{ }^{\circ} \mathrm{C}$ durante o período de condução do experimento. Estas condições ambientais são descritas por Cardoso et al. (5) como propícias para o estabelecimento do patossistema trigo - P. grisea.

A segunda aplicação dos fungicidas foi realizada na fase intermediária da antese, estádio 65 da escala Zadoks et al. (28), correspondendo a 14 dias após a primeira aplicação. A dose utilizada foi semelhante à utilizada na primeira aplicação.

A incidência de brusone na folha bandeira foi avaliada no colmo principal de cada uma das cinco plantas presentes em cada parcela, totalizando cinco avaliações por unidade experimental. Com esses dados, procedeu-se a construção da curva de progresso da doença e a determinação da área abaixo da curva de progresso da doença (AACPD) por meio de equação proposta por Campbell \& Madden (4). Os valores da AACPD foram calculados conforme a equação:

$\mathrm{AACPD}=\sum((\mathrm{Yi}+\mathrm{Y}(\mathrm{i}+1)) \times 0,5) \times(\mathrm{T}(\mathrm{i}+1)-\mathrm{Ti})$, onde $\mathrm{Yi} \mathrm{e}$ $\mathrm{Y}(\mathrm{i}+1)$ são os valores de incidência observados entre as avaliações consecutivas; T $(\mathrm{i}+1)-\mathrm{Ti}$ é o intervalo entre duas avaliações. Os valores de i foram $0,5,7,8,10$ e 14 dias após a inoculação.

Para avaliação da severidade em folhas bandeira (SEVFB), foi utilizado como padrão de avaliação uma planta da unidade experimental. A SEVFB foi quantificada por meio do software QUANTS (26), mensurada na folha bandeira de uma planta de cada parcela. Os dados foram expressos em porcentagem de tecido lesionado da folha.

Determinou-se também a severidade em espigas (SEVEsp), obtida pela relação entre o número de espiguetas infectadas e o número total de espiguetas em cada espiga. Os dados de severidade foram transformados em porcentagem para obtenção dos valores de severidade em espigas, utilizando o seguinte estimador: SEVEsp $=($ Ei x 100)/ TE, em que SEVEsp é a severidade em espigas em porcentagem (\%), Ei é o número de espiguetas infectadas; e TE é o total de espiguetas. Quantificou-se a produção de grãos por unidade experimental após a trilha e padronização da umidade dos grãos para $13 \%$.

As variáveis mensuradas foram submetidas à análise de variância e posterior comparação de médias utilizando o programa computacional GENES (7). Os diferentes parâmetros analisados foram submetidos à análise de correlação de Pearson.

\section{RESULTADOS E DISCUSSÃO}

Para a variável AACPD foi observada interação significativa $(p<0,05)$ entre os fatores genótipos e fungicidas, indicando que a eficiência do controle químico foi dependente do genótipo avaliado e 
vice-versa. Pela análise da Figura 1 é possível inferir que os fungicidas epoxiconazol+piraclostrobina e tebuconazol+trifloxistrobina foram superiores ao fungicida tebuconazol e à testemunha sem aplicação de fungicida para a variável AACPD em todos os genótipos avaliados. Em se tratando da linhagem VI 98053 o controle químico realizado com tebuconazol não se justifica, uma vez que foi ineficiente, não diferindo da testemunha sem aplicação.

Avaliando o comportamento dos genótipos dentro dos níveis do fator fungicidas (Figura 2), observa-se que os fungicidas epoxiconazol+piraclostrobina e tebuconazol+trifloxistrobina foram mais eficientes no controle da brusone nos genótipos VI 03061, VI 07505 e BRS 254 do que no VI 98053. AAACPD não diferiu nos tratamentos com tebuconazol, assim como para a testemunha sem aplicação de fungicida. A superioridade dos fungicidas epoxiconazol+ piraclostrobina e tebuconazol+trifloxistrobina foi evidenciada pela maior redução da AACPD na folha bandeira quando comparado com o tebuconazol em relação à testemunha para todos os genótipos avaliados (Tabela 1). Merece destaque a cultivar BRS 254 que expressou menor AACPD em relação a todos os fungicidas avaliados (Tabela 2).

$\mathrm{Na}$ avaliação de fungicidas para o controle da ferrugem da folha na cultura do trigo Cunha \& Bonaldo (11) observaram redução na AACPD de incidência de 51\% para epoxiconazol+piraclostrobina, $40 \%$ para tebuconazol+trifloxistrobina e $26 \%$ para tebuconazol, quando comparados com a testemunha. Arduim (1) detectou superioridade do fungicida epoxiconazol+piraclostrobina para a ferrugem do trigo, obtendo redução de $85 \%$ da $\mathrm{AACPD}$ em relação à testemunha.

De modo semelhante à AACPD, a variável SEVFB apresentou interação significativa $(p<0,05)$ entre os fatores genótipos e fungicidas, motivando o desdobramento do efeito da interação. Analisando o fator fungicidas dentro dos níveis do fator genótipos fica evidente que os diferentes fungicidas apresentaram a mesma eficiência de controle e superaram a testemunha em todos os genótipos avaliados (Tabela 2). Para o desdobramento do fator genótipos dentro dos níveis do fator fungicidas a diferença no controle é observada apenas para a testemunha sem aplicação de fungicida, ou seja, na ausência de controle químico. Tendo em vista o melhor desempenho dos genótipos VI 98053 e VI 07505 na ausência de controle químico, infere-se que estes apresentam maior nível de tolerância a brusone.

Para a variável produção de grãos, não houve interação significativa entre os fatores genótipos e fungicidas, mostrando que há independência
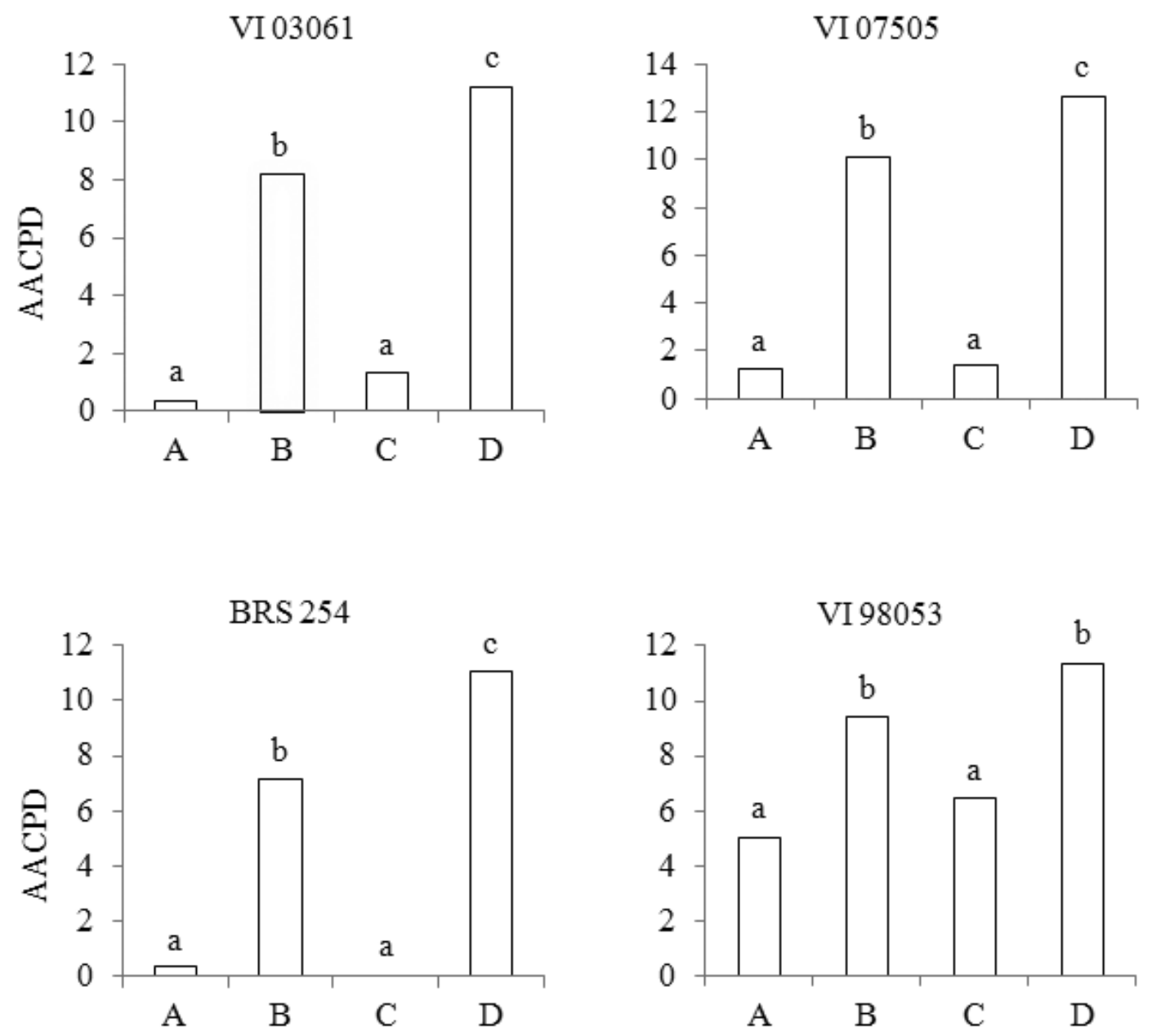

Fungicidas

Fungicidas

Figura 1. Comparação das médias, fator fungicida dentro dos níveis do fator genótipos, para a área abaixo da curva de progresso da doença (AACPD). A= epoxiconazol+piraclostrobina; $\mathrm{B}=$ tebuconazol; $\mathrm{C}=$ tebuconazol+trifloxistrobina; $\mathrm{D}=$ testemunha. Médias seguidas pelas mesmas letras não diferem entre si pelo teste de Tukey $(\mathrm{p} \leq 0,05)$. Viçosa/MG, 2012. 

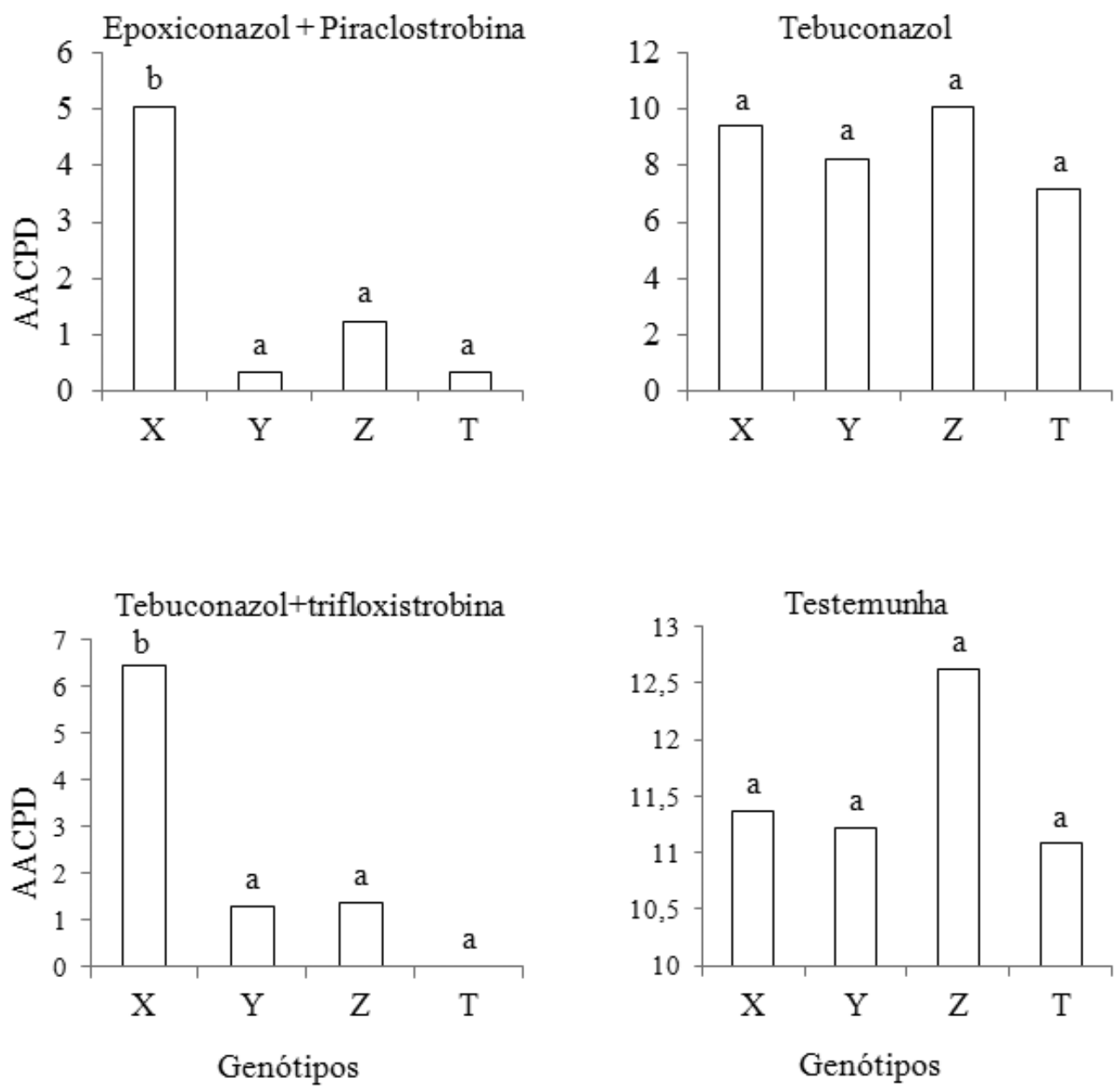

Figura 2. Comparação das médias do fator genótipos dentro dos níveis do fator fungicida para a para a área abaixo da curva de progresso da doença (AACPD). $X=$ VI 98053, Y= VI 03061, Z= VI 07505 e T= BRS 254. Médias seguidas pelas mesmas letras não diferem entre si pelo teste de Tukey (p<0,05). Viçosa/MG, 2012.

Tabela 1. Percentual de redução da área abaixo da curva de progresso da doença em folhas bandeira em relação às testemunhas, obtidas na avaliação da eficiência de fungicidas no controle da brusone em trigo. Viçosa/MG, 2012.

\begin{tabular}{cccc}
\hline \multirow{2}{*}{ Genótipos } & \multicolumn{3}{c}{ Fungicidas } \\
\cline { 2 - 4 } & epoxiconazol+ piraclostrobina & tebuconazol & tebuconazol+ trifloxistrobina \\
\hline VI 98053 & 55,44 & 17,03 & 43,34 \\
VI 03061 & 96,90 & 26,61 & 88,43 \\
VI 07505 & 90,67 & 18,81 & 88,21 \\
BRS 254 & 97,04 & 34,35 & 100,00 \\
\hline Média & $\mathbf{8 5 , 0 1}$ & $\mathbf{2 4 , 2 0}$ & $\mathbf{7 9 , 9 9}$ \\
\hline
\end{tabular}

Tabela 2. Médias de severidade da brusone em folhas bandeira de trigo (\%) obtidas na avaliação da eficiência de fungicidas no controle da brusone em trigo. Viçosa/MG, 2012.

\begin{tabular}{lcccc}
\hline \multirow{2}{*}{ Fungicidas } & \multicolumn{3}{c}{ Genótipos } \\
\cline { 2 - 5 } & VI 98053 & VI 03061 & VI 07505 & BRS 254 \\
\hline Epoxiconazol+piraclostrobina & $2,83 \mathrm{Ab}$ & $1,23 \mathrm{Ab}$ & $0,24 \mathrm{Ab}$ & $0,00 \mathrm{Ab}$ \\
Tebuconazol & $8,56 \mathrm{Ab}$ & $6,20 \mathrm{Ab}$ & $7,28 \mathrm{Ab}$ & $10,47 \mathrm{Ab}$ \\
Tebuconazol+trifloxistrobina & $3,08 \mathrm{Ab}$ & $0,85 \mathrm{Ab}$ & $1,84 \mathrm{Ab}$ & $0,37 \mathrm{Ab}$ \\
Testemunha (sem fungicida) & $74,52 \mathrm{Ba}$ & $97,94 \mathrm{Aa}$ & $75,40 \mathrm{Ba}$ & $96,89 \mathrm{Aa}$ \\
\hline CV (\%) & $\mathbf{3 9 , 5 1}$ & & \\
\hline
\end{tabular}

Médias seguidas pelas mesmas letras minúsculas na vertical e maiúsculas na horizontal não diferem entre si pelo teste de Tukey a 5\% de probabilidade. 
entre os fatores. Realizou-se o teste $\mathrm{F}$ para cada fator e verificouse que houve efeito significativo $(\mathrm{p}<0,05)$ para os dois fatores em estudo, o que indica diferença entre os níveis de cada fator (Tabela 3 ). $\mathrm{Na}$ análise individual do fator genótipos, as linhagens VI 98053, VI 07505 e a cultivar BRS 254 apresentaram média de produção de grãos estatisticamente semelhantes entre si e superiores à linhagem VI 03061.

Quanto aos níveis do fator fungicida, o tebuconazol+trifloxistrobina mostrou-se superior ao epoxiconazol+piraclostrobina e tebuconazol e todos foram superiores à testemunha. $\mathrm{O}$ fungicida tebuconazol+trifloxistrobina possivelmente contribuiu com incrementos na produção de grãos de todos os genótipos avaliados, já que o mesmo não diferiu significativamente do fungicida epoxiconazol+piraclostrobina para as variáveis AACPD, SEVFB e SEVEsp. Por outro lado, o fungicida tebuconazol+trifloxistrobina foi superior aos fungicidas epoxiconazol+piraclostrobina e tebuconazol para o caráter PG. Em trabalho realizado por Scheuermann \& Eberhardt (21) para avaliar fungicidas para o controle da brusone da panícula da cultura do arroz, os tratamento realizados com aplicação de tebuconazol+trifloxistrobina, triciclazol, a sucessão triciclazol/tebuconazol+trifloxistrobina e a mistura em tanque triciclazol+tebuconazol, proporcionaram ganho significativo no peso de mil grãos.

Com relação à SEVEsp não foi obtido efeito significativo entre genótipos e para a interação genótipos x fungicidas. Resultados contrários foram obtidos por Arruda et al., (2), Goulart et al., (17),
Goulart et al. (18) e Urashima \& Kato (24), os quais mostraram que a severidade e os danos causados por brusone variam, sobretudo, com o genótipo de trigo considerado. Para o fator fungicidas, apesar de significativo $(\mathrm{p}<0,05)$, nenhum dos fungicidas apresentou eficiência satisfatória em reduzir a SEVEsp (Tabela 4). Dois dos fungicidas, epoxiconazol+piraclostrobina e tebuconazol, não diferiram da testemunha sem aplicação.

Apesar do resultado satisfatório na redução da AACPD e SEVFB, os fungicidas não foram capazes de controlar a doença em espigas, que constitui a parte econômica. Os danos causados nas espigas são os que proporcionam maiores danos na produtividade de grãos do trigo e na qualidade de farinha. Em trabalhos realizados por Arruda et al., (2), Goulart et al., (17), Goulart et al. (18) e Urashima \& Kato (24) foi relatado que a maioria das cultivares analisada quanto à reação à infecção por $P$. grisea mostrou alta suscetibilidade das espigas à doença.

$\mathrm{Na}$ análise de correlação de Pearson obtida entre as variáveis AACPD, PG, SEVFB e SEVEsp foram detectados resultados significativos $(p<0,01)$ para todos os testes (Tabela 5). Entre as variáveis AACPD x PG, PG x SEVFB e PG x SEVEsp os coeficientes de correlação foram $-0,63,-0,66$ e $-0,69$, respectivamente. Isto indica que as reduções na $\mathrm{PG}$ são proporcionadas pelo aumento da AACPD e/ou da SEVFB e/ou das SEVEsp. Estes resultados são corroborados pela associação existente entre AACPD x SEVFB e AACPD x SEVEsp, com coeficiente de correlação de 0,74 e 0,82 , respectivamente. Entre os caracteres SEVFB e SEVEsp o coeficiente

Tabela 3. Médias da produção de grãos (g) obtidas na avaliação da eficiência de fungicidas no controle da brusone em trigo. Viçosa/MG, 2012.

\begin{tabular}{|c|c|c|c|c|c|}
\hline \multirow{2}{*}{ Fungicidas } & \multicolumn{4}{|c|}{ Genótipos } & \multirow{2}{*}{ Médic } \\
\hline & VI 98053 & VI 03061 & VI 07505 & BRS 254 & \\
\hline Epoxiconazol+piraclostrobina & 2,17 & 1,01 & 2,19 & 2,65 & $2,01 \mathrm{~b}$ \\
\hline Tebuconazol & 1,92 & 1,08 & 2,57 & 1,45 & $1,75 b$ \\
\hline Tebuconazol+trifloxistrobina & 4,69 & 2,52 & 4,42 & 5,89 & $4,39 a$ \\
\hline Testemunha (sem fungicida) & 0,14 & 1,03 & 0,45 & 0,65 & $0,32 \mathrm{c}$ \\
\hline Média & $2,23 \mathrm{~A}$ & $1,16 \mathrm{~B}$ & $2,42 \mathrm{~A}$ & $2,66 \mathrm{~A}$ & \\
\hline
\end{tabular}

Médias seguidas pelas mesmas letras minúsculas na vertical e maiúsculas na horizontal não diferem entre si pelo teste de Tukey a 5\% de probabilidade.

Tabela 4. Médias de severidade da brusone em espigas de trigo (\%) obtidas na avaliação da eficiência de fungicidas no controle da brusone em trigo. Viçosa/MG, 2012.

\begin{tabular}{|c|c|c|c|c|c|}
\hline \multirow{2}{*}{ Fungicida } & \multicolumn{4}{|c|}{ Genótipo } & \multirow{2}{*}{ Média } \\
\hline & VI 98053 & VI 03061 & VI 07505 & BRS 254 & \\
\hline Epoxiconazol+piraclostrobina & 95 & 92 & 87 & 75 & $87,25 \mathrm{ab}$ \\
\hline Tebuconazol & 93 & 95 & 99 & 87 & $93,50 \mathrm{a}$ \\
\hline Tebuconazol+trifloxistrobina & 88 & 71 & 85 & 72 & $79,00 \mathrm{~b}$ \\
\hline Testemunha (sem fungicida) & 100 & 100 & 100 & 100 & $100,00 \mathrm{a}$ \\
\hline Média & $94,00 \mathrm{~A}$ & $89,50 \mathrm{~A}$ & $92,75 \mathrm{~A}$ & $83,50 \mathrm{~A}$ & \\
\hline CV (\%) genótipos: 11,29 & & \multicolumn{4}{|c|}{ CV (\%) fungicidas: 7,44} \\
\hline
\end{tabular}

Médias seguidas pelas mesmas letras minúsculas na vertical e maiúsculas na horizontal não diferem entre si pelo teste de Tukey a 5\% de probabilidade. 
Tabela 5. Coeficientes de determinação e correlação de Pearson entre as variáveis área abaixo da curva de progresso de doença (AACPD), produção de grãos (PG), severidade em folhas bandeira (SEVFB) e severidade em espigas (SEVEsp). Viçosa/MG, 2012.

\begin{tabular}{ccc}
\hline Variáveis & $\mathbf{R}^{2}$ & $\mathbf{r}$ \\
\hline AACPD X PG & 0,3990 & $-0,6317$ \\
PG X SEVFB & 0,4376 & $-0,6615$ \\
PG X SEVEsp & 0,4765 & $-0,6903$ \\
AACPD X SEVFB & 0,5489 & 0,7409 \\
AACPD X SEVEsp & 0,6872 & 0,8290 \\
SEVFB X SEVEsp & 0,3964 & 0,6296 \\
\hline
\end{tabular}

de correlação foi de 0,63 .

Em trabalho de Cruz (8), onde foram avaliados 70 genótipos de trigo inoculados com 18 isolados monospóricos de $P$. grisea, verificouse correlação de 0,15 a 0,77 entre SEVFB e SEVEsp considerando 12 genótipos de trigo e todos os isolados testados.

A identificação de fontes de resistência à brusone em trigo, bem como de novas moléculas fungicidas eficientes no controle da doença, proporcionaria grandes incrementos em produtividade e qualidade da farinha produzida no Brasil, uma vez que a aplicação de fungicidas é eficiente em folhas bandeira, mas não em espigas.

\section{AGRADECIMENTOS}

Ao Conselho Nacional de Desenvolvimento Científico e Tecnológico (CNPq) e à Fundação de Amparo à Pesquisa do Estado de Minas (FAPEMIG) pelo apoio financeiro.

\section{REFERÊNCIAS BIBLIOGRÁFICAS}

1. Arduim, G.S. Sensibilidade de raças de Puccinia triticina a fungicidas. 2009. 91f. Tese (Doutorado em Agronomia) - Universidade de Passo Fundo, Passo Fundo.

2. Arruda, M.A.; Bueno, C.R.N.C.; Zamprogno, K.C.; Lavorenti, N.A.; Urashima, A.S. Reação do trigo à Magnaporthe grisea nos diferentes estádios de desenvolvimento. Fitopatologia Brasileira, Brasília, DF, v.30, p.121-126, 2005.

3. Brasil. Ministério da Agricultura, Pecuária e Abastecimento (MAPA). Coordenação-Geral de Agrotóxicos e Afins/DFIA/SDA. Agrofit. Brasília, DF, 2011 Disponível em: <http://agrofit.agricultura.gov.br/agrofit_cons/ principal_agrofit_cons $>$. Acesso em: 11 jun. de 2012.

4. Campbell, C.L.; Madden, L.V. Introduction to plant disease epidemiology. New York: John Wiley, 1990. 532 p.

5. Cardoso, C.A.A.; Reis, E.M.; Moreira, E.N. Development of a warning system for wheat blast caused by Pyricularia grisea. Summa Phytopathologica, Botucatu, vol.34, n.3, p. 216-221, 2008

6. Comissão Brasileira de Trigo e Triticale. Informações técnicas para trigo e triticale-safra 2012. Dourados: Embrapa Agropecuária Oeste, 2011.218p.

7. Cruz, C.D. GENES - a software package for analysis in experimental statistics and quantitative genetics. Acta Scientiarum, Maringá, v.35, n.3, p. 271-276, 2013.

8. Cruz, M.F.A. Caracterização do padrão molecular e de virulência de isolados de Pyricularia grisea do trigo. 2008. 105f. Dissertação (Mestrado em Agronomia/Área de Concentração em Fitopatologia) - Universidade de Passo Fundo, Passo Fundo.

9. Cruz, M.F.A.; Diniz, A.P.C.; Rodrigues, F.A.; Barros, E.G. Aplicação foliar de produtos na redução da severidade da brusone do trigo. Tropical Plant Pathology, Brasília, v.36, n.6, p.424-428, 2011.

10. Cruz, M.F.A.; Prestes, A.M.; Maciel, J.L.N.; Scheeren, P.L. Resistência parcial à brusone de genótipos de trigo comum e sintético nos estádios de planta jovem e de planta adulta. Tropical Plant Pathology, Brasília, v.35, n.1, p.024-031, 2010.

11. Cunha, O.A.C.; Bonaldo, S.M. Eficiência de fungicidas no controle de ferrugem da folha na cultura do trigo. Campo Digital, Campo Mourão, v.1, n.2, p.72-78, 2008.

12. Dario, G.J.A.; Manfron, P.A.; Bonnecarrére, R.A.G.; Neto, D.D.; Martin, T.N.; Crespo, P.E.N. Controle químico de brusone em arroz irrigado. Revista da Faculdade de Zootecnia, Veterinária e Agronomia, Uruguaiana, v.12, n.1, p.25-33, 2005.

13. Demant, L.A.R.; Maringoni, A.C. Controle da mancha angular do feijoeiro com uso de fungicidas e seu efeito na produção das plantas. Idesia, Arica, v.30, n.2, p. 93-100, 2012.

14. Garcés-Fiallos, F.R.; Forcelini, C.A. Controle comparativo da ferrugem asiática da soja com fungicida triazol ou mistura de triazol + estrobilurina. Bioscience Journal, Uberlândia, v. 29, n. 4, p. 805-815, 2013.

15. Gonçalves, F.J.; Araújo, L.G.; Silva, G.B.; Filippi, M.C.C. Controle químico da brusone em arroz de terras altas: efeitos nos fungos não alvos do filoplano. Pesquisa Agropecuária Tropical, Goiânia, v.42, n.1, p.77-81, 2012.

16. Goulart, A.C.P.; Paiva, F.A. Avaliação de fungicidas no controle da brusone (Pyricularia oryzae) do trigo (T. aestivum). Fitopatologia Brasileira, Brasília, DF, v.18, p.167-173, 1993.

17. Goulart, A.C.P.; Paiva, F.A.; Andrade, P.J.M. Relação entre a incidência da brusone em espigas de trigo e a presença de Pyricularia grisea nas sementes colhidas. Fitopatologia Brasileira, Brasília, DF, v.20, n.2, p.184-189, 1995.

18. Goulart, A.C.P.; Sousa, P.G.; Urashima, AS. Danos em trigo causados pela infecção de Pyricularia grisea. Summa Phytopathologica, Botucatu, v.33, n.4, p.358-363, 2007.

19. Maciel, J.L.N.; Danelli, A.L.D.; Boaretto, C.; Forcelini, C.A. Diagrammatic scale for the assessment of blast on wheat spikes. Summa Phytopathologica, Botucatu, v.39, n.3, p. 162-166. 2013.

20. Neto, D.D.; Dario, G.J.A.; Martin, T.N.; Bonnecarrère, R.A.G.; Manfron, P.A.; Júnior, P.A.V. Controle químico da ferrugem asiática na cultura da soja em condições de campo. Revista da Faculdade de Zootecnia, Veterinária e Agronomia, Uruguaiana, v.14, n.1, p.69-80, 2007.

21. Scheuermann, K.K.; Eberhardt, D.S. Avaliação de fungicidas para o controle da brusone de panícula na cultura do arroz irrigado. Revista de Ciências Agroveterinárias, Lages, v.10, n.1, p.23-28, 2011

22. Takami, L.K. Resistência à Pyricularia grisea em genótipos de trigo. 2011. 65f. Dissertação (Mestrado em Fitotecnia) - Universidade Federal de Viçosa, Viçosa.

23. Urashima, A.S. Genetic analysis of Magnaporthe grisea pathogenicity on wheat. Fitopatologia Brasileira, Brasília, DF, v.24, p.567-569, 1999.

24. Urashima, A.S.; Kato, H. Pathogenic relationship between isolates of Pyricularia grisea of wheat and other hosts at different host developmental stages. Fitopatologia Brasileira, Brasília, DF, v.23, p.30-35, 1998.

25. Urashima, A.S.; Lavorent, N.A.; Goulart, A.C.P.; Mehta, Y.R. Resistance spectra of wheat cultivars and virulence diversity of Magnaporthe grisea isolates in Brazil. Fitopatologia Brasileira, Brasilia, DF, v.29, n.5, p.511$518,2004$.

26. Vale, F.X.R.; Fernandes Filho, E.I.; Liberato, J.R. QUANT. A software plant disease severity assessment. In: International Congress of Plant Pathology, 8., 2003, Christchurch. Anais. Christchurch: New Zealand, 2003. p.105.

27. Vieira, R.V.; Carneiro, J.E.S.; Paula Júnior, T.J.; Teixeira, H. Resposta de feijões de três grupos comerciais ao emprego de fungicidas. Revista Ceres, v.54, n. 316, p. 534-540, 2007.

28. Zadoks, J.C.; Chang, T.T.; Konzak, C.F. A decimal code for the growth stages of cereals. Weed Research, Oxford, v.14, p. 415-421, 1974. 